\title{
Advanced content generation for E-learning using Web mining
}

\author{
Midhun Mahesan', Mohamed Sabith ${ }^{2}$, Ms Sujitha $M^{3}$. \\ ${ }^{1}$ Student,Mangalam College of Engineering, Kottayam, Kerala, India, \\ ${ }^{2}$ Student,Mangalam College of Engineering, Kottayam, Kerala, India, \\ ${ }^{3}$ AssistantProfessor, Mangalam College of Engineering, Kottayam, Kerala, India,
}

\begin{abstract}
E-learning tends to be a promising tool for education in the present era due to its inherent flexibility and convenience. The various methods like synchronous and asynchronous learning technique will be able to serve the people better and meet their requirements. Providing quality education through advanced content and information seems to be challenging in many cases due to the nature of educational information especially in the area of fast growing technology. As internet is a vast source of information with latest content, the same can be effectively utilized through web mining to improve the learning scenario. The knowledge level of the learner and the interest of the person and their context etc also seems to be addressed for developing effective learning system.
\end{abstract}

Key words- Web mining, IoT, e-learning, Education, Clustering, Machine Learning

\section{INTRODUCTION}

A vast majority of the problems that the world is facing today, including poverty, unemployment and social disputes all account for the illiterate population worldwide. Children who are educated tend to overcome these scenarios and are capable of surviving better in the modern world. Even though education is a major concern for all, the cost involved and difficulty in accessibility, especially in rural areas pose challenges to many. The most common problems that hinders the growth of education in rural areas can be pointed out as Lack of proper transportation. Most villages have poor connectivity from one place to another and that is often one of the main reason why, despite efforts by local governing bodies to build schools, often go in vain. Children, most of the time have to walk miles to reach these government funded schools and this often demotivate them to attend school on a regular basis.
People belonging to remote rural areas have meagre incomes, which at times is too less to sustain a family of maybe four or five. Most likely, children from these families won't be sent to schools, instead would be asked to assist the earning member of the family to add up some extra income. On the other hand, teachers in rural educational centres in villages are paid poorly, often leading to lack of attention by teachers, ultimately forcing the students to suffer. Lack of proper infrastructure at these rural schools is also a big concern. Most of the schools don't have proper classrooms, teaching equipment, etc.. Thus, the poor condition of schools is big reasons to drive away students .

Even if there is a person to teach for free, he/she many not be able to teach the entire subject and manage the class simultaneously. So our project is designed to provide an aid in this scenario.

The product is a software that can take the syllabus/course contents including the schedule in which it is to be taught as input and accordingly the software is capable of performing a live lecture from the data it outsourced from various sources from the Internet.

The lecture/presentation is basically the summary of information gathered from the Internet, which has undergone a filtering algorithm. The text is represented as such and the text itself is converted to audio in real time for better understanding.

Furthermore, the product supports voice recognition, hence the student is able to ask queries during the lecture and the questions are processed and answered by collecting data from the Internet as mentioned before. These steps are so fast, hence information will be provided precisely and efficiently to the students.

The product can be used in multiple ways depending on the platform it is designed to operate. 
For example, if the software is installed on a computer which is connected to a projector, the system will be able to take class to a group of students, provided there is an instructor for monitoring the process and furnishing any clarification that may occur due to linguistic mismatch [1].

The software can also be made available to individual students, in the form of IoT enabled device or as an Android application[4],[7].

In all the above mentioned cases, the system will be acting as an educational assistant that can assist the student in their daily study needs.

\section{KEY FEATURES}

Compared to existing systems, the software has a lot of advantages. Distance education and distance training are examples of means of instructional delivery that afford the learner the opportunity to engage in learning experiences away from the traditional classroom. They are planned and structured means of learning that use electronic technology-based media including audio, print, video, and the Internet, alone or in combination[4],[7].

\subsection{LESS DATA CONSUMPTION}

The software is designed to work in lowest speeds of internet, and it only requires internet connectivity for query transfer and receiving text based data. Comparing this system to an alternative platform like online course websites, which offer variety of video lectures and course contents for different courses, the size of data which needs to be received is large and requires high speed internet.

\subsection{UNIVERSAL APPLICATION}

While the online video courses are for one time use and are course specific, the python software is capable of teaching any kind of information that is available from the internet and any number of times[4],[5].

A student need to enrol and download course contents for each course but by using the software the student can save a lot of time, data and money, since the product is a onetime investment and as it can collect huge amounts of data from the Internet, it is capable of teaching various courses[6].

\section{WORKING}

The software is written in python and make use of several APIs of different search engines like Web crawlers, Wikipedia, Wolfram Alpha etc.. which provide the information after taking the query as input. The program consists of algorithms that can filter the input and assign the inputted query to respective API that can provide the best information [3]. For example, when it comes to mathematical problems, the input will be given to Wolfram Alpha API. All the APIs used in the program are under MIT- free to use licence. Furthermore, the proposed model is capable of refining the results through clustering algorithms, provided there is a well managed database.

The data that is provided are in the form of plain text that can be displayed using 'WX' GUI add-on for Python. The text is then converted to audio using 'win-speech' for better understanding and clarity.

\section{TEACHING METHODOLOGY}

The aim is to make teaching in schools as efficient as possible through all means of communication including, visual, audio and repetitive methods [1].

The software can take an entire syllabus or just the curriculum/schedule for the day and take lecture accordingly. To increase student engagement and in order to make the whole process more interactive, the students can ask questions/queries during the lecture itself. The questions can be asked directly to the software through voice recognition or it may be inputted as text. The answers to these queries are retrieved the same way the software fetches the lecture contents.

In order to make the learning process more efficient, the software is intended to follow a system of teaching which follow Bloom's taxonomy, which includes: Creating, Evaluating,

Analysing, Applying, Understanding and Remembering. 


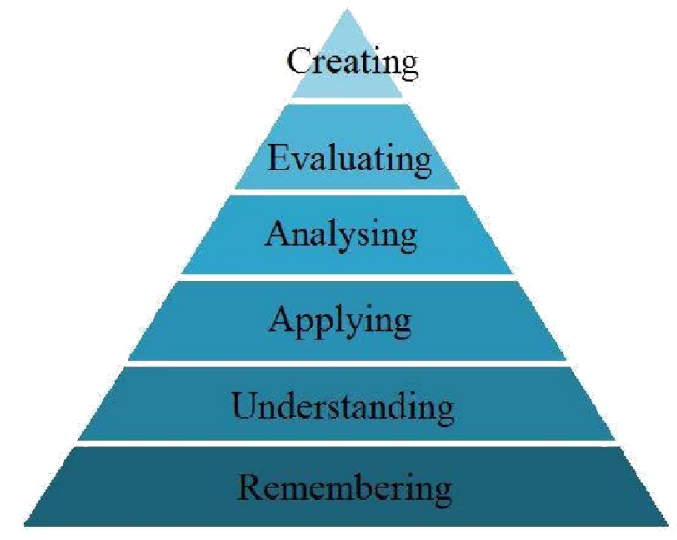

Figure 1 : Bloom's taxonomy pyramid.

\section{IMPLIMENTATIONS}

The concepts discussed above can be implemented using various technologies depending upon user's needs and the area in which the system is supposed to function. For example, if the system is meant for an individual, then the software can be made available as an Android application or software embedded in an IoT based device meant to work in scarcity of resources, especially in rural areas. So the implementations are as follows[2],[3].

\subsection{SOFTWARE AS AN EXECUTABLE FILE}

The executable file can be generated for the software which can then be executed on any operating system like Windows, Mac OS, Linux, etc.. The executable file can be made available on a website which can be downloaded by the end users.

\subsection{ANDROID APPLICATION}

The same system model can be implemented using Java programming, which is the programming language used in Android development platforms like Android Studio and Eclipse.

The Android version of the application will be a lite version compared to the actual software. Hence the application must be connected to a server, in which case we use a client-server model. So the request received by the android application will be sent to the server where the actual application is stored and it then performs the web-mining process of collecting data and the required tutorial content is framed and sent to the Android application. The whole process is done in seconds based on the internet speed and type of query sent.

\subsection{IOT ENABLED HAND HELD DEVICE}

The primary objective is to provide educational aid to areas where traditional system fails and is hard to implement. These are areas where electricity and high-speed internet facilities are a scarcity. So a low-cost device can be implemented with the help of IoT which includes a basic display, micro controller and wifi module [2].

This system can only be implemented with the help of Government bodies and organizations which provide free internet services to rural areas. The device can be powered using solar energy by using a 9V solar panel. But in order to reduce costs even further, a crank mechanism can be implemented which can convert mechanical energy to electrical energy. The combination of this is enough to charge the whole device.

\section{TESTING AND ANALYSIS}

The system has been tested for its satisfaction, accuracy of the information provided, speed of retrieval of data, behaviour of system in different internet speeds and linguistic errors that may occur due to difficulty in recognizing various accents.

From testing, out of various challenges faced by the system, the main challenge was recognizing voice of users, especially young students, who are the majority of end users of the system. This challenge was overcome by adding an option of voice recognition as well as text input, where in on subsequent errors of audio recognition, the system will ask to input the query/question through the text input of GUI. A text prediction system is also made active to predict what may be the query, which is based of pattern recognition from previous searches made by other users. 


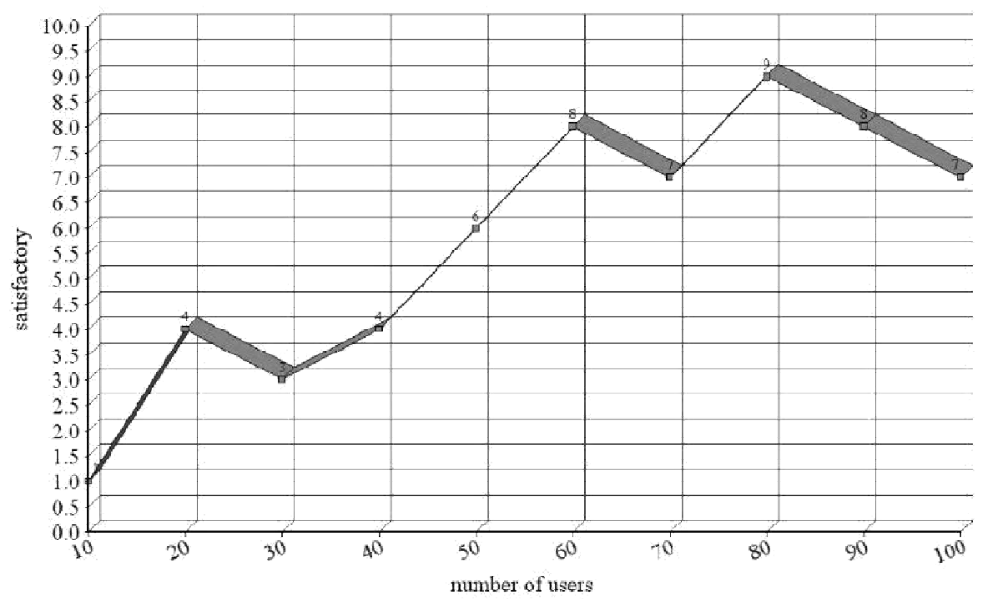

Figure 2 :satisfaction curve of varying number of end users.

\section{REFERENCES}

[1] M.O. Hagler, W.M. Marcy, J.R. Yeargan, K.R. Laker, R.L. Sullivan, D.A. Conner "The making of the special issue on the application of information technologies to engineering and science education": IEEE Transactions on Education Volume: 39 , Issue: 3 pp. 450 - 451, Aug 1996 .

https://doi.org/10.1109/13.538772

[2] Bridget Benson, Arash Arfaee, Choon

Kim, Ryan Kastner, Rajesh K. Gupta”

Integrating Embedded Computing Systems Into High School and Early

Undergraduate Education": IEEE

Transactions on Education Volume: 54, Issue: 2, pp. 197 - 202 , September 2010.

[3] L. Fallow "Engineering education for the future": Engineering Science and

Education Journal Volume: 5 , Issue: 5 ,pp. 196 200, Oct 1996 . https://doi.org/10.1049/esej:19960501

[4] Monica Ciolacu, Ali Fallah Tehrani, Leon Binder, Paul Mugur Svasta "Education 4.0 - Artificial Intelligence Assisted Higher Education: Early recognition System with Machine Learning to support Students'

Success": 2018 IEEE 24th International

Symposium for Design and Technology in Electronic Packaging, SIITME, 25-28 Oct. 2018.

[5] Sandra Gama, Daniel Gonçalves

"Visualizing Large Quantities of Educational Datamining Information": 2014 18th International Conference on Information Visualisation, 16-18 July 2014.
[6] Andrés González-Nucamendi, Julieta Noguez, Luis Neri, Víctor Robleda-Rella "Predictive models to enhance learning based on student profiles derived from cognitive and social constructs": 2015 International Conference on Interactive Collaborative and Blended Learning ICBL, 9-11 Dec. 2015.

[7] Oswaldo Moscoso-Zea, Sergio LujánMora "Educational data mining: An holistic view": 2016 11th Iberian Conference on Information Systems and Technologies CISTI, 15-18 June 2016. 